\title{
A Little Less Conversation, a Little More Action: Participatory Insider Action Research in an Executive Team
}

\author{
David Kenefick $^{1} \cdot$ Melrona Kirrane $^{1}$ (D)
}

Received: 10 February 2021 / Accepted: 11 October 2021

(c) The Author(s) 2021, corrected publication 2022

\begin{abstract}
In this paper, we describe a Participatory Insider Action Research (PIAR) intervention within the Executive Committee (EC) of a large publicly funded service for people with intellectual disabilities. I was a member of this EC and had been for 20 years. The intervention ran over a two-year period and comprised three cycles of PIAR. We addressed two specific organisational issues but our work did not deliver change in these areas in a substantial sense. We identify power dynamics and role duality challenges as the core factors that contributed to this outcome and describe their effects in this under-researched domain. We finish by offering some advice for future researchers undertaking initiatives of this nature.
\end{abstract}

\section{Introduction}

The Executive Committee (EC) of any organisation is tasked with highly significant responsibilities and obligations and many tools and techniques are available to support these activities (Lisiński and Šaruckij (Lisiński and Šaruckij 2006); Webster et al. (Webster et al. 1989)). Notwithstanding the value that such prescribed approaches to strategic operations can offer, they have been criticised for being bureaucratic, rigid and detached from organisational realities (Mintzberg (Mintzberg 1994)). Action Research (AR) is an embedded approach to organisational analysis and development (Bradbury (Bradbury 2015); Brydon-Miller and Coghlan (Brydon-Miller and Coghlan 2014); Erro-Garcés and AlfaroTanco (Erro-Garcés and Alfaro-Tanco 2020)). Its purpose, among others, is to deliver learning and enhanced capacity to respond to issues and challenges as they arise (Shani and Coghlan (Coghlan and Shani 2017); Wenger (Wenger 1998)). In this sense, its potential to richly contribute to responding to the strategic challenges of an organisation is clear.

The organisation in which this study took place is a large publicly funded service for people with intellectual disabilities. Its purpose is to enrich the lives of people with an intellectual disability and support them in achieving their potential by providing a wide

Melrona Kirrane

Melrona.kirrane@dcu.ie

David Kenefick

david.kenefick2@mail.dcu.ie

1 Dublin City University Business School, Dublin 9, Ireland 
range of professional, educational and support services. All the activities of this organisation are guided by the principal of maximising the independence of people with disabilities. Its services are anchored in the values of personalisation, professionalism and integrity and continual improvement in these services is a key priority.

While there are many techniques whereby organisational enrichment can occur (Cameron and Green (Cameron 2019)), alignment between context and method is critical (Kang and Chang (Kang 2019)). A core concern of AR is the pursuit of worthwhile human purpose (Reason and Bradbury 2001). Its values include empowerment, social change, supportive relationships and learning (Nelson et al. (Nelson et al. 1998)). Such values are wellaligned with the desire for human flourishing at the core of this organisation and thus an AR intervention was undertaken to support us in delivering our intent.

\section{Action Research}

Action research is an emergent inquiry process in which applied behavioural science knowledge is integrated with existing organisational knowledge and used to address live organisational issues (Coghlan and Brannick (Coghlan and Brannick 2014)). It is an evolving process that is undertaken in a spirit of collaboration and co-inquiry (Shani and Pasmore (Shani 1985)). In its purest form, it is a process whereby members of a social system gather and use data about themselves to undertake both remedial and developmental action (Lewin 1946). The phases of AR comprise observing, describing, considering and reflecting on action, followed by taking action, monitoring what happens, reflecting on outcomes, analysing data, and coming to conclusions (Berlinck, and Saito (Berlinck and Saito 2010)). Resting on a Principal Researcher's explicit and tacit knowledge of the organisation, these steps are repeated in a spiral of cycles leading to the development of new knowledge which can be brought to bear on the circumstances at hand (Altrichter et al. (Altrichter et al. 2002)). AR has been used across a diverse range of settings and business functions to date, ranging from fashion (Radaelli et al. (Radaelli et al. 2014)) to media (Walton and Gaffney (Walton and Gaffney 1989)), policy (Larrea and Arrona (Larrea and Arrona 2019)) and electronics (Fredberg et al. (Fredberg et al. 2011); Schuiling 2014). Its application in top management teams is rare by comparison (Coghlan and Brydon-Miller (Coghlan 2014)).

Reflection is a key and distinctive element of action research (Coghlan and Brannick (Coghlan and Brannick 2014); McKernan (McKernan 1996)). It involves a complex process of observing, recording, reflecting, conceptualising, concluding and learning. Such reflection requires transparency and involves intense questioning of researchers' assumptions, conceptualisations of events and planning for action (Winter and Munn-Giddings (Winter 2001)). Kakabadse, Kakabadse, and Kalu ((Kakabadse et al. 2007)) clarify that in AR there needs to be both reflectionon action, which looks back on experience and reflection in action, which refers to real-time learning or 'in vivo' reflexivity' (p. 258).

Reflection is supported by dialogue which offers a space for participants to exchange ideas and thus enrich reflections (Coghlan and Shani (Coghlan et al. 2014)). Dialogue is a process of discovering, exploring and interrogating interpretations to achieve understanding or agreement (Tsang (Tsang 2007)). Dialogic encounters may not always be democratic and indeed can be a conduit for power when the dialectical space is claimed by strong individuals or when participants self-censor their contributions to avoid conflict (Burbules (Burbules 2002)). Efforts must be made, therefore, to bring about effective dialogue by 
equalizing power holdings (Freire 1970) such that differences between participants are surfaced in a spirit of truth, sincerity and legitimacy and brought to bear on seeking resolutions to problems as reflected Habermas's ((Habermas 1986)) ideal speech situation. In this way, meaningful reflection is supported.

Insider Action Research (IAR) involves AR being carried out by a 'complete member' of an organisation in and on their own organisation (Coghlan and Brannick (Coghlan and Brannick 2014); Paltved et al. (Paltved et al. 2016)). Participatory Insider Action Research (PIAR) occurs when people taking part in the research are participants in, rather than subjects of, the research (Brannick and Coghlan (Brannick and Coghlan 2007); Gustavsen (Gustavsen 2008); Humphrey (Humphrey 2007)). This entails the participants being involved in selecting the research topic, collecting and analysing data, and deciding on action (Baum et al. (Baum et al. 2006)). Within PIAR studies, the highest level of participation is self-mobilisation in which participants set their own agenda and organise for action, affording research and knowledge-building to operate in a democratic manner (lisahunter and Martin (lisahunter et al. 2013); Melrose (Melrose 2001); Smith et al. (Smith et al. 2010)).

Studies have demonstrated that all forms of IAR are complex and raise many challenges (MacIntosh et al. (MacIntosh et al. 2007); Nyman et al. (Nyman et al. 2016)). Two key challenges have been widely discussed in the literature, namely role duality and power dynamics (Holian and Coghlan (Holian and Coghlan 2013); Jacobs (Jacobs 2010); Smith et al. (Smith et al. 2010)). Role duality arises when the IARr carries one role as an organisational member while simultaneously holding a role as a researcher. While roles help organise dimensions of thinking, feeling and acting (Landy (Landy 2009)) and shape behavioural expectations (Sluss and Ashforth (Sluss and Ashforth 2007)), holding multiple roles often complicates relationships between role set members leading to confusion, conflict and contradictions for the researcher and colleagues alike (Moore (Moore 2007); Ravitch and Wirth (Ravitch and Wirth 2007); Smyth and Holian (Smyth and Holian 2008)).

Power dynamics are visible in the possession of control, authority and influence over work tasks and processes (Avison et al. (Avison et al. 2007)) and are a particular feature of management teams (Patel and Cooper (Patel and Cooper 2014); Tarakci et al. (Tarakci et al. 2016)). Managing power dynamics within AR interventions requires the continuous and skilled negotiation of power (Aime et al. (Aime et al. 2014); Beckett and Myers (Beckett and Myers 2018)). It requires the IARr to act as a political entrepreneur and demonstrate a range of hard and soft skills to build participation and promote engagement (Buchanan and Badham (Buchanan and Badham 1999)). It requires the simultaneous management of the two Janus perspectives of deep involvement in a continuous and long-term ongoing change activity, while also striving for reflective distance and rigorous analysis through empathic and political involvement (Levin (Levin 2012)).

\section{The Context of the Study}

The organisation where this study took place was established in Ireland in 1955 and has over 1,000 employees. It provides a wide range of services to almost two thousand people with intellectual disabilities and their families. These services comprised clinical, residential, home and independent living support as well as education, training and research.

The environment of this organisation was characterised by a high degree of stability and predictability within a context of strong fiscal rectitude. A traditional, top-down approach 
to management prevailed and change evolved carefully and cautiously as befits a publicly funded body. The EC was a well-functioning team where decisions were made appropriately and matters were dealt with effectively (Salas et al. (Salas et al. 2018)). The atmosphere was constructive and collegial, and reflected the collaborative learning atmosphere necessary for AR interventions (Shani and Coughlan 2019). Team members had a long history of working together and respected each other's professional and personal competence. They were deeply committed to the purpose of the organisation and were driven to delivering on its strategic intent to the best of their abilities.

At the point in time of this intervention the organisational environment was largely calm. Besides the not insignificant requirement to steer the organisation effectively, there was no immediate crisis for the EC to respond to nor critical decisions to be made. These contextual advantages, along with the earlier described alignment of values between the organisation's objectives and research philosophy, it was an opportune time to suggest the incorporation of a new way of working in the pursuit of our mission. Thus, the initiative was in no way remedial, but instead was envisioned to be one of growth and optimisation of the capacities of the EC in the service of delivering on the organisation's purpose.

\section{Research Participants}

All seven members of the EC, which included the CEO, constituted the research group. Tenure of members on the EC ranged from eight to twenty years. We each had distinct professional and managerial backgrounds, and while sitting on the EC rendered us nominally equal, primus inter pares circumstances arose according to the agenda item being discussed and related expertise and responsibilities. Over the period of the PIAR, two members retired with one of these being replaced by a new incumbent towards the end of the PIAR.

\section{Research Process}

The research began with a pre-step where I approached each member of the EC individually to discuss the idea of incorporating PIAR into our operations on the EC. I explained the nature of AR and its spirals of action and identified the centrality of participation, confidentiality, anonymity and equality as key ethical characteristics of PIAR. I highlighted that reflection is a core activity and that keeping reflective journals would be helpful. I explained the concept of 'communicative space' (Habermas (Habermas 1986)) and emphasised that group decision-making would be an integral feature of the process. As part of this description, I described the matters of role duality and power dynamics and the possible challenges they may incur on the process. It was important to be explicit about these issues at this point, not only because some people on the team had stronger power bases due to their interpersonal style and personality characteristics (Anderson et al. (Anderson et al. 2012); Lasswell (Lasswell 2017)), but also due to the salience of the positional power of the CEO. I felt that raising these issues would help insure they were not 'taboo' subjects as the PIAR proceeded and would help each person become aware of and establish an identity as an equal-status co-researcher and support them in navigating the issues that may 
arise. Interestingly, my colleagues identified with these matters and seemed relieved they were brought out into the open.

During these meetings, I shared my pre-understanding of the organisation which I proposed would serve as the foundation to the PIAR. The four issues I offered included:

1. Our approach to service development.

2. Our inclusion of organisational stakeholders in service development.

3. Our use of planned and emergent approaches to organisational change.

4. The manner in which we undertake project reviews.

Thus informed, I invited them to take some time to consider engaging with my proposal and to revert with their responses. Each member consented to participate in the process and thus the PIAR was launched.

Three major AR cycles took place, all of which were larger than many documented AR cycles (Molineux and Haslett (Molineux and Haslett 2002); Torbert and Taylor (Torbert 2008)). In fact, the cycles closely resembled the messiness of AR as described by Cook ((Cook 2009)) and McNiff and Whitehead ((McNiff and Whitehead 2002)). Each Cycle comprised a number of group sessions (GS) which were interspersed with individual and sub-group work which contributed to the planning of subsequent Cycles (Revans (Revans 1980)). Cycle 1 consisted of five group sessions over seven months, Cycle 2 consisted of nine group sessions over eleven months, while Cycle 3 lasted six months and consisted of eight group sessions.

\section{Validity and Reliability}

Recognising that "the principal threat to the validity of action research comes from the lack of impartiality on the part of the researcher" (Coughlan and Coghlan (Coughlan and Coghlan 2002), p. 237), I embedded many practices that served to protect the process from this threat. I engaged in continuous negotiation, reflexivity and dialectical engagement with all co-researchers thus avoiding bias and consensus (Denzin and Lincoln (Denzin and Lincoln 2008)). I engaged in thorough record-keeping with team members and ensured collective agreement of the accuracy of these details by circulating draft records to everyone for input (Coghlan and Shani (Coghlan and Shani 2005); Eikeland (Eikeland 2006)). These techniques, supported by the collaborative use of a core research group, repetition of the spirals of action research cycles, triangulation of data, reflective journals and my use of a critical friend (Foulger (Foulger 2010)) ensured the participatory nature of the process and protected the validity, reliability and ethical rigour of the study (Brydon-Miller et al. (Brydon-Miller et al. 2006); Ravitch and Wirth (Ravitch and Wirth 2007)).

I drew on the idea of an Hermeneutic Circle (Bontekoe, (Bontekoe 1996)) to inform how the data were analysed. This concerns creating a dialectic for understanding the whole in the interpretation of its parts such that the analysis moves between emic and etic perspectives (Pike (Pike 1967)). The emic position was fulfilled by us jointly analysing the data to extract knowledge to inform action, while the etic criterion was satisfied drawing on mind maps, charts and diagrams created within group and inter-sessional work (Luke et al. (Luke et al. 2014)). Working to gain distance from personal assumptions required repeated reading of the records, undertaking further analysis prompted by these reviews and welcoming challenges on assumptions and interpretations. Reference to the relevant literature 
further supported the objectivity of this process (Melrose (Melrose 2001); Zuber-Skerritt and Fletcher (Zuber-Skerritt and Fletcher 2007)).

\section{The Story of the Research}

\section{Cycle One}

The EC had a scheduled meeting on the morning of the day when the team was due to meet for the first PIAR Group Session (GS). I found myself behaving differently in this meeting as I was already anxious about the PIAR session that afternoon. It was scheduled to begin at $2 \mathrm{pm}$ but I was asked to push out the start time by thirty minutes. My anxiety to launch the project led me to accede to this request. Thus even before the process formally began, I could detect the power dynamics and role duality challenges that are characteristic of PIAR.

When the first session finally began, I re-introduced the research more formally and reminded everyone about the value of reflection as part of the PIAR. I sought their feedback on the ideas I had shared with them earlier and encouraged their participation in building on or adjusting these suggestions. After a good discussion, we developed two of these four issues into clearer themes to be the focus of our work and captured them under the following headings:

1. Clarification of the role of the EC in relation to service development.

2. Stakeholder inclusivity within the organisation's mission, vision and values.

We briefly discussed these matters and then wrapped the session with an agreement to think about them before the next session. I wrote up a record of the session and circulated it to capture any amendments, a practice I continued throughout the initiative.

GS 2 took place six weeks later and began with reports from the co-researchers on the development of their thoughts in the intervening period. No new ideas were presented so we got together in pairs to progress our two core themes. By the end of this session, three issues emerged with respect to progressing our first theme: firstly, that the EC had a role in relation to service development; secondly, that its role in this space was less clear than its role in relation to other areas of the organisation, and finally that the role should be clarified and likely change as a result. We did not progress our second theme. We agreed again to meet up in pairs before the next GS to continue our discussions.

GS 3 took place 4 weeks later than planned to accommodate others' diaries. This was the second time I acceded to requests to adjust the timetable of the PIAR and while not ideal, I conceded in the spirit of collaborative engagement. I kicked it off with a reminder of the planning, implementing, observing and reflecting phases of the AR spiral and our use of it to support our work. Each pair presented their inter-session work but again little new content was visible. As our discussions proceeded, it struck me that the more powerful people were those who suggested topics for consideration, directed discussions and drew conclusions, while the less powerful people supported the proposals of the former, acquiesced with their suggestions. We continued to discuss the two themes but did not reach any conclusions. I was asked to provide a content overview of the sessions to date and a set of questions to support members' progress. I was reluctant to provide such a framework for 
our work in case it would obstruct the flow of the PIAR process, however I agreed to this request while recording myself as being "too conforming".

Even in these early sessions the power dynamics were visible and I felt I was constantly trying to counter what I saw as the over-control by some other members. I noted "Everyone isn't contributing to this process". I began to think that a tighter structure of the sessions would support more equal participation, but I was conscious of the need to avoid directing the process myself. As a result, I made no change to my modus operandi but felt quite conflicted. I discussed my approach with my critical friend who encouraged me to avoid providing too much direction.

I also found myself caught up in role duality such that although I consciously enacted distinct PIAR behaviours resting on the principal of equality, my thoughts within the PIAR were seeping out to influence my behaviour in the EC and my thoughts as I carried out my EC role were equally seeping out to influence my behaviour in the PIAR. I noted: "The dual role issue is starting to have a major impact on all of my behaviour" and discussed my management of this with my critical friend. I also heard back from other team members that they reacted to recommendations and contributed to decisions in the PIAR with one eye on how such interactions may impact relationships with other members in their EC roles. This was a clear expression of their own experiences of the challenges of role duality.

At that point in the PIAR, about five months into the process, the serious matter of a national economic crisis began to unfold. The likely impact of this on the organisation was a major concern for us in our EC roles and it distracted attention from the PIAR. When we did re-group for GS4, only the least powerful members had done any inter-session work. There was a brief general discussion about the complexity of service development, but no consensus on how to action this emerged, nor any plan for inter-session work. I was disappointed with this but reconciled the low level of PIAR activity as an inevitable consequence of the economic crisis.

I was anxious in anticipation of the last session of this Cycle, not least because it was going to be the first major review of the research, but also due to the additional burden we were under with respect to the fallout from the financial crisis. The session got underway and as we reviewed the activities of the PIAR, I was heartened to hear team members endorse its value. They noted that it provided 'protected space' for thinking and discussion with: "It creates an opportunity to communicate at a personal and revealing level based on shared participation and transparency." In discussing how Cycle two should proceed, there was an insistence that whatever we do, the next cycle had to be characterised by action. My desire for Cycle 2 concerned enhancing equal participation of all co-researchers and increasing our use of reflection and I discussed how to achieve this with my critical friend.

\section{Cycle Two}

At the first GS of Cycle 2, I provided an overview of what we had done so far but people were still distracted and anxious amidst the now keenly-felt pressures of the economic recession. A suggestion was made by a powerful member to remove the two topics from the PIAR and deal with them instead within the context of the EC. I interpreted this as a desire for the attention of members to be fully placed on the organisation's response to the crisis and it was a blow to me as it would herald the end of the PIAR. I discussed it later with my critical friend who supported me to see it as 'a possible and undesirable outcome but one that had to be accepted as an outcome nonetheless'. In any event, with others 
having endorsed the value of PIAR at the end of Cycle 1, there was no consensus on taking this path and the session finished with a commitment to consider how we could connect the work of the PIAR with the wider organisational environment and so render our work more meaningful.

When we met for GS2, only I had any thoughts to present on linking our work to the prevailing organisational challenges but my suggestions on how we could do this did not gain any traction. I was confused by this given the sentiment at the end of the previous session and wondered whether it reflected a preference among some members to have such serious issues as the financial crisis dealt with within the formality of the EC and not the less structured context of the PIAR. At the same time, others commented that keeping the two issues separate would protect the PIAR from the stressful atmosphere of dealing with the financial crisis. I saw this as reflecting an awareness of the value of PIAR although I wondered whether this was an implicit suggestion that the matters the AR was working on were not important and so could be left within it without a connection with the real context. We agreed that before the next session, we would work in pairs to propose where we go from here with respect to our two core themes rather than link our work to the organisational environment. I was asked to prepare a briefing document to enable the co-researchers to do this work and I conceded to this as a means of supporting the PIAR.

The third GS took place after a number of postponements. Co-researchers presented what they had been working on and again it was clear that the more powerful people had done least inter-session work while the less powerful people had done most. We still struggled with deciding on the next steps for progressing our two core themes. Some team members voiced their frustration with how slow this was going with one more powerful person criticising the process as "...very long-winded ... going around in circles". This sounded like criticism of me and was uncomfortable. One team member noted that this slow and repetitive process reflected how we operated when engaged in our EC role. While this sounded like a criticism of the EC, I also saw it as an indicator of engaging in reflective work which was positive. Ultimately there was no agreement on actions to progress our work on either theme. Instead, the same person as before suggested I work with one other person to develop the learning from Cycle 1 and that one other pair identify a project within our two core themes on which to take action. I noted 'There is dominance of the discussion, which is impacting how people contribute to the overall thinking of the group'. I found this repeated suggestion from the same individual that I should revisit the data quite frustrating because I felt these tasks should have been undertaken by us all in a collaborative manner. By agreeing to do so in the spirit of supporting the process, I felt I was reinforcing EC dynamics rather than allowing space for new PIAR dynamics to emerge. I found this time tiring, stressful and discouraging and my critical friend was helpful at this time.

At the next session (GS4), my review of the learning from Cycle 1 prompted a good level of discussion and I noted: "It really felt like the communicative space was starting to be used more". However, we did not come to any agreement on action in relation to our core themes. I agreed to circulate trigger questions to support the inter-session work on identifying paths for action and to collate responses received with two other members.

At the next session (GS5), rather than continue where we left off, we returned to the topic of linking the prevailing national financial crisis to our work on service development and this time we agreed to move in this direction. I saw this as a positive step and an advantage to both the PIAR and the organisation. This decision, however, did not result in the identification of any clear steps to take in this regard. I agreed to work with two others 
to identify tasks for the group in relation to this during the inter-session break. While this session appeared to be productive, I found the absence of any decision on action quite frustrating. In thinking about it I concluded that I needed to recalibrate my expectations about what could be achieved, thinking "...action research really does go where people want". I wondered whether I had been applying my EC expectations for progress on to the AR rather than accepting its own pace.

I ended up doing the inter-session work alone and brought it to the next GS (6) where energy levels seemed low. Instead of progressing the connection between the economic crisis and the PIAR, our discussion moved to away from this topic and focused on the second theme of the PIAR concerning the inclusivity of stakeholders in our mission, vision and values statements. This was the first time this theme received our attention beyond its introduction at the start of the PIAR. We discussed some ideas around this issue, noting "To date, our mission statement has been undefined, too general.... too many words attempting to encompass all aspects of everything". We agreed to further our thoughts on it during the inter-session break while also maintaining the momentum around the topic of service development.

At the next session (GS7), just two people had work to present on our mission and vision and values. This detailed a number of options for rewriting the organisation's existing statements in a more inclusive manner. We discussed these but did not finalise any agreement. We resumed this discussion at the next session (GS8) and expanded it to consider how our values get embedded in organisational processes and activities. This discussion continued at the final GS of Cycle 2 where we explored appropriate terminology, addressed the challenges of implementing values in practice and examined our conceptions of the people who received the organisation's services in the light of these values. While this was a rich discussion, we did not agree on what to do next with respect to these issues and with no further reference to our work in relation to the role of the EC in service development, the Cycle ended.

I felt quite deflated at this point, with: "It is akin to the most intensive and demanding aspects of my [day] job". Postponements and gaps had led to interruption of the work and resulted in confusion and repetition while the challenges of responding to the economic crisis added further pressure. Again, my critical friend supported me at this time. Dealing with role duality and power dynamics had not become any easier either. I was aware that these dynamics reflected the need for people to protect their EC roles and relationships and I recorded: "I still feel that I am not doing well at enabling everyone to have an equal voice. I probably do not have enough skills or power".

\section{Cycle Three}

I opened the first session of Cycle three seeking members' views on whether or not the PIAR should continue. I did so in order to give everyone an opportunity to state their commitment or otherwise to proceed. While people noted that "It took time to become confident in the process", everyone agreed that it should continue because it "...brought a 'task' focused group together to view their collective role in a more collaborative way". I was pleased with this and heartened by the constructive tone. At the next session I proposed a six-month timeframe for the completion of the PIAR which we agreed. I suggested we resume where we left off at the end of Cycle 2 and continue to focus on the topic of mission, vision and values. We agreed a detailed plan for continuing this work and I noted 
"I'm happy with how I got the group to decide what to do and how to do it rather than me telling them".

Four members of the group, again the less powerful members, progressed this work before the next session where we continued to discuss it. At that session (GS3), one person suggested that we distinguish between the mission of the organisation and its vision and values, in that the former was something we could continue to work on ourselves, while the latter should properly include the voices of wider organisational stakeholders. To achieve this, it was agreed that work on the vision and values would be removed from further consideration in the PIAR, while work on the mission would be retained within its remit. While I agreed that this was an appropriate path to take, I felt there was pressure to consent due to the power of the proposer and the manner in which the proposal was driven until agreement was achieved. We then turned our attention to the matter of the organisation's mission and there was broad consensus that changing societal views on the dignity and independence of people with disabilities need to be more explicitly articulated within our documentation. One member offered to work on this during the break between sessions.

At the next session (GS4), there was broad agreement on the new draft mission statement that was presented. This constituted a partial deliverable from the PIAR and was satisfying to note, although we agreed this had to be formally ratified in the EC environment for it to take effect. We then re-focussed on the one remaining issue of the PIAR, namely the EC's role in relation to service development. Two pairs of co-researchers agreed to explore this further before the next session but only one pair actually delivered on this.

We built on this work at GS5 but confusion surrounding it soon became apparent. One person said they weren't even clear on what the term 'service development' meant. Yet again it was suggested that I and three others undertake a review of the records of all three Cycles to help clarify our thoughts on it and feed it back to GS6. I didn't think this was necessary but the records were reviewed nonetheless and the findings were brought back to the next session. At this session (GS6), moving this topic out of the PIAR to be dealt with by the EC was suggested but not agreed, because it was argued that the PIAR was the correct location for its completion. Instead, the topic was split into two parts with two people agreeing to focus on the role of the EC in the organisation, while myself and another team member would consider the definition of service development.

At the next session (GS7), there was broad agreement that the EC's role in relation to service development needed to change with respect to three areas: devolution of power and responsibility, development of an outcome focus and enhanced listening to the voices of service users. No action steps for translating these ideas into substantial change were identified. While it was good to have some further ideas in relation to this theme, I was tired and frustrated by our repeated inability to agree on a way forward and the continued submission of some members to more powerful others. I was worried that the same powerful person would dominate the final session and reduce the quality of our discussion. I would have been happy if the PIAR had ended then. Two of us canvassed the opinions of the rest of the team as to the format of the last session but no ideas were forthcoming.

The last session took place as planned, two years from the beginning of the main research. Its purpose was to finalise our thoughts on the role of the EC in relation to service development. As anticipated, this session was dominated by the same person who made a set of proposals for action in relation to the three issues from the previous session. However, our allotted time expired before we reached any agreement. As the PIAR closed with little substantial outcome, I wondered how effective I had been, noting "The big question for me is, could I have fed back to them/challenged them in a way/ways that would have enabled decisions and actions". 


\section{Discussion}

This study comprised three AR cycles within a PIAR framework which ran over a two-year period within the executive team of a large publicly funded service for people with intellectual disabilities. The study was intended to clarify the role of the EC in service development and address the inclusivity of stakeholders in our mission, vision and values. In line with the premises of AR to enhance diffusion of ideas and lead to change in individual behaviour and organisational practices (Elden and Taylor (Elden and Taylor 1983)), it was anticipated that this work would initiate relevant organisational changes.

The PIAR produced a re-draft of our mission statement which was to be formally adopted and ratified by the EC. We also progressed our documentation on vision and values to a point where wider organisational consultation was recommended and brought back to the EC. That we did not finalise these documents within the PIAR left me with a question as to how much the EC rather than the PIAR was the final arbiter of them. In line with the objective of organisational learning that is central to AR (Weil (Weil 1998)), we covered a lot of ground with respect to considering the role of the EC in relation to service development and I believe our understanding of its complexity was enhanced. We agreed this role needed to change with respect to three areas: devolution of power and responsibility, development of an outcome focus and enhanced listening to the voices of service users. However, we did not deliver the clarification of this role as intended. We now identify and discuss some factors that we believe contributed to these outcomes. In doing so, we illuminate the complexities of PIAR within the context of an executive team and add new insights concerning the challenges of PIAR.

Differences in roles and associated power among co-researchers have been clearly identified as influencing AR outcomes (Coghlan and Brannick (Coghlan and Brannick 2014)). Despite the nominal equality that existed between members of the PIAR, and commitment to the principle of equality by each co-researcher, the formal EC roles and informal interpersonal power differences of members held considerable sway in the operations of the PIAR. They were visible in more powerful people dominating discussions and determining PIAR activity, and less powerful members acceding to their proposals and submitting to their requests. These outcomes align with the studies of Gorinski and Ferguson ((Gorinski 1997)) and Krim ((Krim 1988)) and reflect the inextricable connection between power and action whereby the dominant discourse drives consensus (Gaventa and Cornwall (Gaventa 2008)). Domination, as a face of power (Fleming and Spicer (Fleming and Spicer 2014)) determines the terrain of action and non-action (Alvesson (Alvesson 1987)) and was clearly visible in this study. The manner in which this occurred may reflect a degree of subjectification among the co-researchers (Townley (Townley 1993)) in that what appeared to be free behaviour, had, in fact, strong power-related qualities (Costea et al. (Costea et al. 2008); Knights and Willmott (Knights and Willmott 1989)). This subjectification, whereby co-researchers had internalised their identity as members of the EC and had absorbed its dominant truths (Alvesson and Willmott (Alvesson and Willmott 2002); Boje (Boje 1995); Riad (Riad 2005)), strongly influenced their behaviour and operated as an additional form of covert power (Fleming and Spicer (Fleming and Spicer 2014)). It normalized the submission of less powerful members to more powerful others (Goss et al. (Goss et al. 2011)) and was clearly portrayed in differing levels of participation by members.

This submission dynamic may also reflect the perception of the less powerful members that there could be consequences for their roles as EC members from how they participated in the context of the PIAR. This may have served to reinforce and maintain the 
'EC-related' behaviours while limiting the possibility of acting differently in the context of the research. These findings reflect the complex and paradoxical nature of power (Finkelstein (Finkelstein 1992); Keltner (Keltner 2016)) and the difficulties associated with attempts to reformulate power relations (Van Bunderen et al. (Van Bunderen et al. 2018)).

An additional explanation for these dynamics may lie in the longevity of tenure on the EC of the co-researchers. This had given rise to a set of understandings and expectations of interaction patterns that had become embedded in the norms of the group (Chatman and Flynn (Chatman and Flynn 2001); Uzzi and Spiro (Uzzi and Spiro 2005)). As a result of their familiarity with each other as members of the EC, co-researchers interacted in recognisable and predictable ways were able to anticipate each other's contributions. Such behavioural dynamics are never easy to dislodge especially when behaviours underpinned by them have served the group well in the past (Grønhaug and Olsen (Grønhaug 1999)), but they make for an arduous path when interaction patterns from new role sets are sought (Coghlan and Casey (Coghlan and Casey 2001)).

As a result of this long-standing engagement with each other, the social exchange relations co-researchers had developed with each other (Pfeffer (Pfeffer 1992)) activated the norm of reciprocity and the dynamics of commitment and obligation. These relations rendered the governance structures and acceptable behaviours to be durable attributes of co-researchers' relationships which were difficult to displace and allow space for new styles of interaction that would have supported the PIAR. Instead, these relations facilitated the preservation of covert control among more powerful members and made it difficult for participants to move into new roles as co-researchers (Krackhardt (Krackhardt 1990)).

I was highly attuned to these power-related tensions. In holding multiple roles, each of which was vested with power in its own right, I worked hard to minimise the impact of these bases of power within the PIAR, not just to support its activity, but also to protect my relationships with all EC members. Maintaining a balance between these conflicting demands was a challenge throughout the study and is at the core of managing any AR process (Mohrman and Cummings (Mohrman and Cummings 1989); Teusner (Teusner 2016)). These tensions influenced my thinking and behaviour, largely in the form of self-regulation in line with the experiences of Moore ((Moore 2007)) and Ravitch and Wirth ((Ravitch and Wirth 2007)). I recognise that the combination of my unwillingness to challenge the group and the absence of means to disrupt the routines of the group resulted in 'business as (EC) usual' being maintained as a practice and dynamic within the PIAR.

Within the AR literature, little attention is paid to the organisation's external environment and how it affects AR projects. In this study, the national economic crisis which unfolded over the course of the PIAR was impossible to ignore. It triggered significant changes in relation to finance, staffing and operations and influenced the thinking, priorities and behaviour of the co-researchers. While the rationale for the research was ultimately to enrich the capacities of the EC to advance its strategic imperative, the crisis provoked managerial entrenchment and strong alignment of behaviour with formal EC roles. It led to a swift regression to the well-established configuration of power relations (Barthol and $\mathrm{Ku}$ (Barthol and $\mathrm{Ku}$ 1959)). At one level this was understandable due to the organisational responsibilities held by the EC. However, the implications for the PIAR were that there was less focus on equality within the group, reduced attention for the PIAR and more frustration with its dynamics. The urgency and importance of the crisis strengthened preferences for directive leadership and led to a reduction in the time, attention and priority given to the research. It further resulted in much of the content issues of the PIAR being relocated into the formal activities of the EC. This is at odds with the philosophy of AR which positions its activity within organisational realities (Coghlan et al. (Coghlan et al. 2014)). Perhaps it is the case that the utility of the PIAR had 
not been sufficiently established by the time the crisis hit during Cycle 1, leading to a rapid reinstatement of habitual practices of leadership, followership and group behaviour (Michael and Robbins (Michael and Robbins 1998)). While McDaniel, Jordan, and Fleeman ((McDaniel et al. 2003)) highlight the opportunity presented by 'surprises' that occur within AR and refer to such developments as 'gifts', the surprise in the form of sudden changes in the external environment was not seen as 'promising opportunities for new approaches to meeting organisational goals'(McDaniel et al. (McDaniel et al. 2003): 267), but, rather, as a threat. Being willing to 'question, explore, and experiment.' (275) in the face of this 'surprise' was difficult for the co-researchers.

\section{Lessons for Future PIAR Researchers}

PIAR is not straightforward and is subject to the vagaries of role duality and power dynamics. Spending more time at the start of such a project thoroughly explaining the tenets of this method, detailing its implications for new behaviours and interaction patterns and securing commitment to engage with such requirements is recommended as a route to limiting the impact of these challenges. The nature and dynamics of power, as well as the demands of operating out of dual roles simultaneously, need to be explicitly addressed with advice provided on how to handle them. Concepts such as psychological safety (Edmondson (Edmondson 1999)) could be introduced to encourage participants to divest themselves of formal power roles and to enter into the AR space where power operates according to a different rhythm.

Limited reflection among co-researchers further complicated this study and I recognise that I did not sufficiently support the practice. While time was allocated to this at each GS, I too easily allowed it fall off the agenda when I sensed the atmosphere was not conducive. This meant that my reflections were less connected to any other reflections being undertaken by team members, thus diluting the contribution of the process to the PIAR. Future PIARrs should not allow the priority of reflection to be side-lined. Over the course of a PIAR study, participants should be assisted in using it with dedicated time for reflection featuring in every group session.

To finish, notwithstanding the difficulties outlined, I still consider PIAR to be an eminently worthwhile activity. It enriched my appreciation of the complexities of organisational change and development and highlighted the need for deep wells of behavioural science based resources to support it. Armed with realistic expectations of what can be achieved and the psychological fortitude to sustain engagement, there is much to endorse it as an insight-building, growth-oriented process that can confer meaningful benefits on all concerned.

Funding Open Access funding provided by the IReL Consortium.

\section{Declarations}

Data Privacy Statement The data that support the findings of this study are available upon reasonable request from the corresponding author $[\mathrm{MK}]$. The data are not publicly available due to them containing information that could compromise research participant privacy. 
Open Access This article is licensed under a Creative Commons Attribution 4.0 International License, which permits use, sharing, adaptation, distribution and reproduction in any medium or format, as long as you give appropriate credit to the original author(s) and the source, provide a link to the Creative Commons licence, and indicate if changes were made. The images or other third party material in this article are included in the article's Creative Commons licence, unless indicated otherwise in a credit line to the material. If material is not included in the article's Creative Commons licence and your intended use is not permitted by statutory regulation or exceeds the permitted use, you will need to obtain permission directly from the copyright holder. To view a copy of this licence, visit http://creativecommons.org/licenses/by/4.0/.

\section{References}

Aime F, Humphrey S, DeRue DS, Paul JB (2014) The riddle of heterarchy: Power transitions in cross-functional teams. Acad Manag J 57(2):327-352

Altrichter H, Kemmis S, McTaggart R, Zuber-Skerritt O (2002) The concept of action research. The Learning Organisation 9(3):125-131

Alvesson M (1987) Organizations, culture, and ideology. Int Stud Manag Organ 17(3):4-18

Alvesson M, Willmott H (2002) Identity regulation as organizational control: Producing the appropriate individual. J Manage Stud 39(5):619-644

Anderson C, John OP, Keltner D (2012) The personal sense of power. J Pers 80(2):313-344

Avison D, Baskerville R, Myers MD (2007) The structure of power in action research projects. Information Systems Action Research. Springer, Boston, pp 19-41

Barthol RP, Ku ND (1959) Regression under stress to first learned behavior. J Abnorm Soc Psychol 59(1):134-136

Baum F, MacDougall C, Smith D (2006) Participatory action research. J Epidemiol Commun Health 60(10):854

Beckett C, Myers MD (2018) Organizational culture in Business Process Management: The challenge of balancing disciplinary and pastoral power. Pac Asia J Assoc Inf Syst 10(1):3

Berlinck CN, Saito CH (2010) Action research for emancipation informed by Habermas and hierarchy of systems: case study on environmental education and management of water resources in Brazil. Syst Pract Action Res 23(2):143-156

Boje DM (1995) Stories of the storytelling organization: A postmodern analysis of Disney as "TamaraLand". Acad Manag J 38(4):997-1035

Bontekoe R (1996) Dimensions of the hermeneutic circle. Humanities Press, London

Bradbury H (2015) The Sage handbook of action research. Sage, London

Brannick T, Coghlan D (2007) In defence of being "native": The case for insider academic research. Organ Res Methods 10(1):59-74

Brydon-Miller M, Coghlan D (2014) The big picture: Implications and imperatives for the action research community from the SAGE Encyclopedia of Action Research. Action Res 12(2):224-233

Brydon-Miller M, Greenwood D, Eikeland O (2006) Strategies for addressing ethical concerns in action research. Action Res 4(1):129-131

Buchanan D, Badham R (1999) Politics and organizational change: The lived experience. Hum Relat 52(5):609-629

Burbules NC (2002) The limits of dialogue as a critical pedagogy. Revolutionary pedagogies. Routledge, Abingdon, pp 273-295

Cameron E, Green M (2019) Making sense of change management: A complete guide to the models, tools and techniques of organizational change. Kogan Page Publishers, London

Chatman JA, Flynn FJ (2001) The influence of demographic heterogeneity on the emergence and consequences of cooperative norms in work teams. Acad Manag J 44(5):956-974

Coghlan D, Brannick T (2014) Doing action research in your own organization. Sage, London

Coghlan D, Brydon-Miller M (eds) (2014) The SAGE encyclopaedia of action research. Sage, London

Coghlan D, Casey M (2001) Action research from the inside: issues and challenges in doing action research in your own hospital. J Adv Nurs 35(5):674-682

Coghlan D, Shani AR (2005) Roles, politics, and ethics in action research design. Syst Pract Action Res 18(6):533-546

Coghlan D, Shani AB (2017) Inquiring in the present tense: the dynamic mechanism of action research. J Chang Manag 17(2):121-137

Coghlan D, Shani AB, (Rami), (2014) Creating action research quality in organizationdevelopment: Rigorous, reflective and relevant. Syst Pract Action Res 27:523-536 
Coghlan D, Shani AR, Roth J, Sloyan RM (2014) Executive development through insider action research: Voices of insider action researchers. J Manag Dev 33(10):991-1003

Cook T (2009) The purpose of mess in action research: building rigour though a messy turn. Educ Action Res 17(2):277-291

Costea B, Crump N, Amiridis K (2008) Managerialism, the therapeutic habitus and the self in contemporary organizing. Hum Relat 61(5):661-685

Coughlan P, Coghlan D (2002) Action research for operations management. Int J Oper Prod Manag 22(2):220-240

Denzin NK, Lincoln YS (2008) Introduction: The discipline and practice of qualitative research. In: Denzin NK, Lincoln YS (eds) Strategies of qualitative inquiry. Sage Publications Inc, London, pp $1-43$

Edmondson A (1999) Psychological safety and learning behavior in work teams. Adm Sci Q 44(2):350-383

Eikeland O (2006) Condescending ethics and action research: Extended review article. Action Res 4(1):37-47

Elden M, Taylor JC (1983) Participatory research at work: An introduction. J Occup Behav 4(1):1-8

Erro-Garcés A, Alfaro-Tanco JA (2020) Action research as a meta-methodology in the management field. Int J Qual Methods 19:1609406920917489

Finkelstein S (1992) Power in top management teams: Dimensions, measurement, and validation. Acad Manag J 35(3):505-538

Fleming P, Spicer A (2014) Power in management and organization science. Acad Manag Ann $8(1): 237-298$

Foulger TS (2010) External conversations: An unexpected discovery about the critical friend in action research inquiries. Action Res 8(2):135-152

Fredberg T, Norrgren F, Shani ABR (2011) Developing and sustaining change capability via learning mechanisms: A longitudinal perspective on transformation. Research in organizational change and development. Emerald Group Publishing Limited, London

Freire P (1970) Cultural action and conscientization. Harvard Educational Review 40(3): $452-477$

Gaventa J, Cornwall A (2008) Power and knowledge. The Sage handbook of action research: participative inquiry practice, vol 2. Sage, Los Angeles, London, New Dlhi, Singapore, p 172-189

Gorinski R, Ferguson P (1997) (Ex)changing experiences of insider research. Paper presented at the New Zealand Association for Research in Education Conference, Auckland

Goss D, Jones R, Betta M, Latham J (2011) Power as practice: A micro-sociological analysis of the dynamics of emancipatory entrepreneurship. Organ Stud 32(2):211-229

Grønhaug K, Olson O (1999) Action research and knowledge creation: merits and challenges. Qual Market $\operatorname{Res} 2(1): 6-14$

Gustavsen B (2008) Action research, practical challenges and the formation of theory. Action Res 6(4):421-437

Habermas J (1986) The new obscurity: the crisis of the welfare state and the exhaustion of utopian energies: translated by Phillip Jacobs. Philos Soc Crit11(2):1-18

Holian R, Coghlan D (2013) Ethical issues and role duality in insider action research: Challenges for action research degree programmes. Syst Pract Action Res 26(5):399-415

Humphrey C (2007) Insider-outsider: Activating the hyphen. Action Res 5(1):11-26

Jacobs G (2010) Conflicting demands and the power of defensive routines in participatory action research. Action Res 8(4):367-386

Kakabadse NK, Kakabadse AP, Kalu KN (2007) Communicative action through collaborative inquiry: journey of a facilitating co-inquirer. Syst Pract Action Res 20(3):245-272

Kang YS, Chang YJ (2019) Sharing the voice and experience of our community members with significant disabilities in the development of rehabilitation games. Syst Pract Action Res 32(1):1-12

Keltner D (2016) The power paradox: How we gain and lose influence. Penguin, London

Knights D, Willmott H (1989) Power and subjectivity at work: From degradation to subjugation in social relations. Sociology 23(4):535-558

Krackhardt D (1990) Assessing the political landscape: Structure, cognition, and power in organizations. Adm Sci Q 35:342-369

Krim R (1988) Managing to Learn: Action Inquiry in City Hall. In: Reason P (ed) Human inquiry in action: developments in new paradigm research. Sage, London, pp 144-162

Landy R (2009) Role theory and the role method of drama therapy. Current Approaches in Drama Therapy 2:65-88

Larrea M, Arrona A (2019) Improving the approach to conflict in action research through deliberative policy analysis: A territorial development case in the Basque Country. Policy Stud 40(5):492-509 
Lasswell HD (2017) Power and personality. Routledge, Abingdon

Levin M (2012) Academic integrity in action research. Action Res 10(2):133-149

Lewin K (1946) Action research and minority problems. 2(4):34-46

lisahunter E, Emerald, Martin G (2013) Participatory activist research in the globalised world: Social change through the cultural professions. Springer, Dordrecht

Lisiński M, Śaruckij M (2006) Principles of the application of strategic planning methods. J Bus Econ Manag 7(2):37-43

Luke H, Lloyd D, Boyd W, Den Exter K (2014) Improving conservation community group effectiveness using mind mapping and action research. Conservation Society 12(1):43-53

MacIntosh R, Bonnet M, Coghlan D (2007) Insider action research: opportunities and challenges. Manag Res News 30(5):335-343

McDaniel RR Jr, Jordan ME, Fleeman BF (2003) Surprise, surprise, surprise! A complexity science view of the unexpected. Health Care Manage Rev 28(3):266-278

McKernan J (1996) Curriculum action research: A handbook of methods and resources for the reflective practitioner. Psychology Press, Hove

McNiff J, Whitehead J (2002) Action research: Principles and practice. Sage, London

Melrose MJ (2001) Maximizing the rigor of action research: why would you want to? How could you? Field Methods 13(2):160-180

Michael SC, Robbins DK (1998) Retrenchment among small manufacturing firms during recession. J Small Bus Manage 36(3):35-40

Mintzberg H (1994) The fall and rise of strategic planning. Harvard Bus Rev 72(1):107-114

Mohrman SA, Cummings TG (1989) Self-designing organizations: Learning how to create high performance. Addison-Wesley, Boston

Molineux J, Haslett T (2002) Working within organizational cycles-A more suitable way to manage action research projects in large organizations? Syst Pract Action Res 15(6):465-484

Moore B (2007) Original sin and insider research. Action Res 5(1):27-39

Nelson G, Ochocka J, Griffin K, Lord J (1998) "Nothing about me, without me": Participatory action research with self-help/mutual aid organizations for psychiatric consumer/survivors. Am J Commun Psychol 26(6):881-912

Nyman V, Berg M, Downe S, Bondas T (2016) Insider Action research as an approach and a methodExploring institutional encounters from within a birthing context. Action Res 14(2):217-233

Paltved C, Morcke AM, Musaeus P (2016) Insider action research and the microsystem of a Danish surgical ward. Action Res 14(2):184-200

Patel PC, Cooper D (2014) Structural power equality between family and non-family TMT members and the performance of family firms. Acad Manag J 57(6):1624-1649

Pfeffer J (1992) Understanding power in organizations. Calif Manag Rev 34(2):29-50

Pike KL (1967) Etic and emic standpoints for the description of behavior. In: Pike KL (ed) Language in relation to a unified theory of the structure of human behavior. Mouton \& Co, The Hague, pp 37-72

Radaelli G, Guerci M, Cirella S, Shani AB (2014) Intervention research as management research in practice: learning from a case in the fashion design industry. Br J Manag 25(2):335-351

Ravitch SM, Wirth K (2007) Developing a pedagogy of opportunity for students and their teachers: Navigations and negotiations in insider action research. Action Res 5(1):75-91

Reason P, Bradbury H (Eds.) (2001) Handbook of action research: Participative inquiry and practice. Sage

Revans RW (1980) Action learning: New techniques for management. Blond and Briggs Ltd., London

Riad S (2005) The power of'organizational culture as a discursive formation in merger integration. Organ Stud 26(10):1529-1554

Salas E, Reyes DL, McDaniel SH (2018) The science of teamwork: Progress, reflections, and the road ahead. Am Psychol 73(4):593

Schuiling G (2014) Changing leadership dynamics at agility-critical interfaces: action research as a 25-year longitudinal study. In Research in organizational change and development. Emerald Group Publishing Limited

Shani AB, Coghlan D (2019) Action research in business and management: a reflective review. Action Research. https://doi.org/10.1177/1476750319852147

Shani AB, Pasmore WA (1985) Organization inquiry: Towards a new model of the action research process. Contemporary Organization development: Current Thinking and Applications Scott, Foresman, Glenview, 438-448

Sluss DM, Ashforth BE (2007) Relational identity and identification: Defining ourselves through work relationships. Acad Manag Rev 32(1):9-32 
Smith L, Bratini L, Chambers DA, Jensen RV, Romero L (2010) Between idealism and reality: Meeting the challenges of participatory action research. Action Res 8(4):407-425

Smyth A, Holian R (2008) Credibility issues in research from within organisations. In: Sikes P, Potts A (eds) Researching education from the inside. Routledge, Abingdon, pp 33-47

Tarakci M, Greer LL, Groenen PJ (2016) When does power disparity help or hurt group performance? J Appl Psychol 101(3):415

Teusner A (2016) Insider research, validity issues, and the OHS professional: One person's journey. Int J Soc Res Methodol 19(1):85-96

Torbert WR, Taylor SS (2008) Action inquiry: Interweaving multiple qualities of attention for timely action. In Reason P, Bradbury H (eds) The SAGE handbook of action research: Participative Inquiry and Practice. Sage, Los Angeles, London, New Delhi, Singapore, p 239-252

Townley B (1993) Foucault, power/knowledge, and its relevance for human resource management. Acad Manag Rev 18(3):518-545

Tsang NM (2007) Reflection as dialogue. Br J Soc Work 37(4):681-694

Uzzi B, Spiro J (2005) Collaboration and creativity: The small world problem. Am J Sociol 111(2):447-504

Van Bunderen L, Greer LL, Van Knippenberg D (2018) When interteam conflict spirals into intrateam power struggles: The pivotal role of team power structures. Acad Manag J 61(3):1100-1130

Walton RE, Gaffney ME (1989) Research, action, and participation: The merchant shipping case. Am Behav Sci 32(5):582-611

Webster JL, Reif WE, Bracker JS (1989) The manager's guide to strategic planning tools and techniques. Plan Rev 17:4-13

Weil S (1998) Rhetorics and realities in public service organizations: systemic practice and organizational learning as critically reflexive action research (CRAR). Syst Pract Action Res 11(1):37-62

Wenger E (1998) Communities of practice: Learning as a social system. Syst Thinker 9(5):2-3

Winter R, Munn-Giddings C (2001) A handbook for action research in health and social care. Psychology Press, Hove

Zuber-Skerritt O, Fletcher M (2007) The quality of an action research thesis in the social sciences. Qual Assur Educ 15(4):413-436

Publisher's Note Springer Nature remains neutral with regard to jurisdictional claims in published maps and institutional affiliations. 